\title{
Collocation Method Based on Bernoulli Polynomial and Shifted Chebychev for Solving the Bratu Equation
}

\author{
EL-Gamel $\mathbf{M}^{*}$, Adel W and EL-Azab MS
}

Department of Mathematical Sciences, Faculty of Engineering, Mansoura University, Egypt

\begin{abstract}
In this work, Bernoulli-collocation method is proposed for solving nonlinear Bratu's type equations. The operational matrix of derivative of Bernoulli is introduced. The matrix together with the collocation method are then utilized to reduce the problem into a system of nonlinear algebraic equations. Also, a reliable approach for solving this nonlinear system is discussed. Numerical results and comparisons with other existing methods provided in the literature are made.
\end{abstract}

Keywords: Bratu's problem; Bernoulli polynomial; Nonlinear; Shifted chebychev

Mathematics Subject Classification Primary: 34B15; Secondary 65N35.

\section{Introduction}

Nonlinear boundary value problems (BVPs) of ordinary type plays an important role in all branches of science and engineering especially the two point BVPs. These types of equations appears in a wide variety of problems including but not limited to chemical reactions, hear transfer and solution of optimal control problems. Therefore, the need for fast and efficient methods for solving this type of equations is a must.

In this work we will develop a collocation approach based on Bernoulli polynomials for solving the famous Bratu's equation in the form

$$
\begin{gathered}
u^{\prime \prime}(x)+\lambda e^{ \pm u(x)=0}, \quad x \in(0,1) \\
\mathrm{u}(0)=u(1)=0
\end{gathered}
$$

The closed form for the exact solution to eqn. (1) is

$$
u(x)=-2 \operatorname{In}\left[\frac{-\cosh \left(\left(x-\frac{1}{2}\right) \frac{\theta}{2}\right.}{\cos \left(\frac{\theta}{4}\right)}\right]
$$

where $\theta$ satisfies $\theta=\sqrt{2 \lambda} \cosh \left(\frac{\theta}{4}\right)$. Eqn. (1) has zero, one or two solutions when $\lambda>\lambda_{c} ; \lambda=\lambda_{c}$ and $\lambda<\lambda_{c}$ respectively, where the critical value $\lambda_{c}$ satisfies the following equation $\lambda_{c}=8 \sec ^{2}\left(\frac{\theta_{c}}{4}\right)$. It was evaluated from that the critical value of $\lambda_{c}$ has a value of $\lambda_{c}=3.513830719$.

This type of equation has many applications including the modelling of a combustion in a numerical slab, the ignition of fuel of the thermal theory, the thermal reaction process modelling, the expansion of the universe model and open questions regarding this theory, chemical reaction theory and nanotechnology [1].

There has been numerous analytic and numerical methods that has been applied for solving Bratu's equation with different forms of exact solutions [2,3]. For instance, B-spline method [4], parametric spline [5], non-polynomial spline [6], quintic spline [7], cubic spline $[8,9]$, Sinc-Galerkin [10,11], lie group shooting [12], Adomian decomposition method [13-17], Homotopy perturbation method
[18-20], optimal perturbation [21], successive differentiation method $[22,23]$, Chebychev wavelet $[24,25]$, Legendre wavelet [26], variation iteration [27-29], iterative finite difference [30], genetic algorithm based methods [31], multi step iterative [32], neural network [33,34], particle swarm shooting [35] and pseudospectral method [36,37]. In addition to the standard Bratu problem, there are other Bratu-type problems which will be introduced and examined later.

Bernoulli polynomials have gained increasing importance in numerical analysis since they are straightforward and need less computational errors. Many researchers have been working on proving the efficiency of this method [38-43].

The organization of the paper is as follows. We recall the basic concepts of Bernoulli polynomials and their relevant properties needed hereafter. Bernoulli method is presented for solving the general Bratu's type equations. Some numerical examples are presented along with a comparison with other techniques. Finally, the closing stage which provides the conclusions of the study [44-47].

\section{Fundamental Relations}

Bernoulli polynomials play an important role in different areas of mathematics, including number theory and the theory of finite differences. They are also can be found in the integral representation of the differentiable periodic functions, since they are employed for approximating such functions in term of polynomials. The classical Bernoulli polynomials $\mathrm{B}_{\mathrm{n}}(\mathrm{x})$ is usually defined by means of exponential generating functions [40].

$$
\frac{t e^{t x}}{e^{t-1}}=\sum_{k=0}^{\infty} B_{k}(x) \frac{t^{k}}{k !}
$$

from which we can find the following known expansion

${ }^{*}$ Corresponding author: EL-Gamel M, Department of Mathematical Sciences, Faculty of Engineering, Mansoura University, Egypt, Tel: 20502383781; E-mail: gameleg@yahoo.com

Received June 15, 2018; Accepted July 13, 2018; Published July 23, 2018

Citation: EL-Gamel M, Adel W, EL-Azab MS (2018) Collocation Method Based on Bernoulli Polynomial and Shifted Chebychev for Solving the Bratu Equation. J Appl Computat Math 7: 407. doi: 10.4172/2168-9679.1000407

Copyright: (c) 2018 EL-Gamel M, et al. This is an open-access article distributed under the terms of the Creative Commons Attribution License, which permits unrestricted use, distribution, and reproduction in any medium, provided the original author and source are credited. 


$$
\sum_{k=0}^{n}\left(\begin{array}{l}
n+1 \\
k
\end{array}\right) B_{k}(x)=(n+1) x^{n}
$$

which is the most known expansion of the Bernoulli polynomials and from we can generate the first few polynomials as Figure 1

$$
\begin{aligned}
& B_{0}(x)=1, \quad B_{1}(x)=x-\frac{1}{2}, \\
& B_{2}(x)=x^{2}-x+\frac{1}{6}, \quad B_{3}(x)=x^{3}-\frac{3}{2} x^{2}+\frac{1}{2} x, \\
& B_{4}(x)=x^{4}-2 x^{3}+x^{2}-\frac{1}{30}
\end{aligned}
$$

these polynomials have many interesting properties from which the following Figure 1

$$
\begin{gathered}
\frac{d B_{n}(x)}{d x}=n B_{n-1}(x), \quad(\mathrm{n} \geq 1), \int_{0}^{1} B_{n}(x) d x=\frac{B_{n+1}(1)-\mathrm{B}_{n+1}(0)}{n+1}, \\
B_{0}(x)=1 \quad B_{n}(x+1)-B_{n}(x)=n x^{n-1}, \\
B_{n}(x+1)=\sum_{k=0}^{n}\left(\begin{array}{l}
n \\
k
\end{array}\right) B_{k}(x), \quad B_{n}(1-x)=(-1)^{n} B_{n}(x) \\
(-1)^{n} B_{n}(-x)=B_{n}(x)+n x^{n-1}
\end{gathered}
$$

In the next we will introduce Bernoulli matrix of differentiation that will be needed later.

\section{Bernoulli operational matrix of differentiation}

We will use Bernoulli approximation technique to approximate the solution of eqn. (1) expressed in the truncated Bernoulli series in the form

$$
u_{N}(x)=\sum_{n=0}^{N} c_{n} B_{n}(x)=\mathbf{B}(x) \mathbf{c}
$$

where $\left\{\mathrm{c}_{n}\right\}_{n=0}^{N}$ are the unknown Bernoulli coe cients, $\mathrm{N}$ is any chosen positive integer such that $\mathrm{N} \geq 2$, and $\mathrm{B}_{\mathrm{n}}(\mathrm{x}), \mathrm{n}=0 ; 1 ;::$; $\mathrm{N}$ are the Bernoulli polynomial of the rst kind which are constructed according to equation (2), the Bernoulli coeffcient vector $\mathrm{c}$ and the Bernoulli vector $\mathbf{B}(\mathrm{x})$ are given by

$$
\mathrm{c}^{\mathrm{t}}=\left[\mathrm{c}_{0} ; \mathrm{c}_{1, \ldots . ., \mathrm{N}_{\mathrm{N}}}\right] ; \quad \mathrm{B}(\mathrm{x})=\left[\mathrm{B}_{0}(\mathrm{x}) ; \mathrm{B}_{1}(\mathrm{x}) ;::: ; \mathrm{B}_{\mathrm{N}}(\mathrm{x})\right] .
$$

According to eqn. (3)

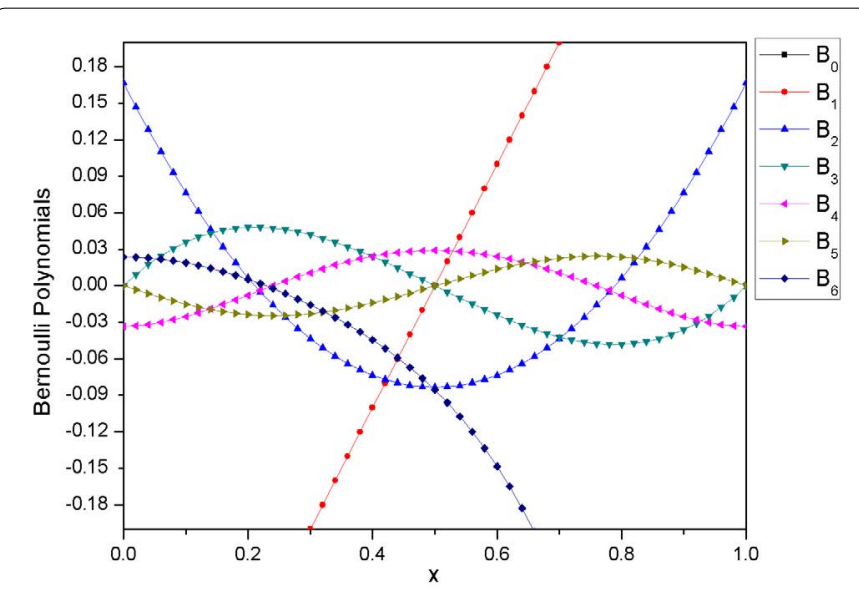

Figure 1: Shows the first few Bernoulli polynomials on the interval $[0,1]$.

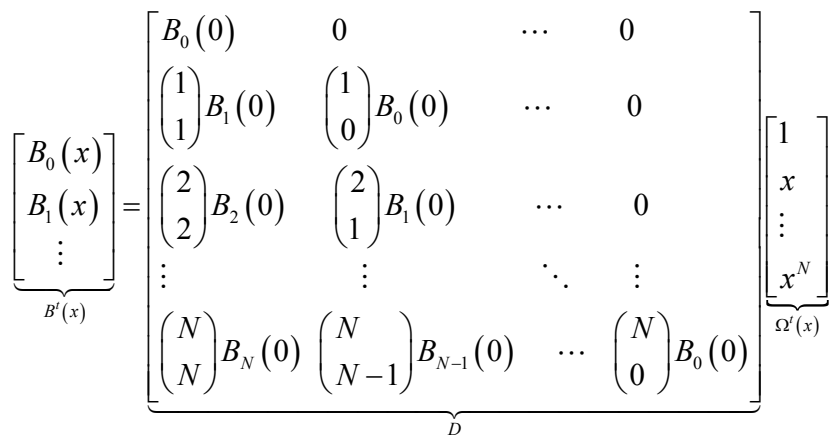

Since $\mathbf{D}$ is a lower triangular matrix with nonzero diagonal elements and $\operatorname{det}(\mathbf{D})=1$, so $\mathbf{D}$ is an invertible matrix. Thus, the Bernoulli vector can be given directly from

$$
\mathrm{B}(\mathrm{x})=\Omega(\mathrm{x}) \mathrm{D}^{\mathrm{t}}
$$

note that [] $]^{\mathrm{t}}$, denotes transpose of the matrix [] and $\mathbf{B}^{\mathrm{t}}(\mathrm{x})$ and $\Omega(\mathrm{x})$ be the $(\mathrm{N}+1) \times 1$ and $\mathrm{D}$ is the $(\mathrm{N}+1) \times(\mathrm{N}+1)$ operational matrix whose elements are

$$
\{\mathrm{D}\}_{i, j=1}^{N+1}=\left\{\begin{array}{l}
\left(\begin{array}{c}
i-1 \\
j-1
\end{array}\right) B_{i-j}, \quad \mathrm{i} \geq \mathrm{j} \\
0, \quad \mathrm{i}<\mathrm{j}
\end{array}\right.
$$

Now, the matrix forms of the solution functions as

$$
\mathrm{y}_{\mathrm{N}}=\Omega(\mathrm{x}) \mathbf{D}^{\mathrm{t}} \mathrm{c}
$$

According to the eqn. (5) the following formula is concluded evidently. Also, the relation between $\Omega(\mathrm{x})$ and it's ith derivative $\Omega^{(1)}$ (x) is

$$
\Omega^{(1)}(x)=\underbrace{\left[1, \mathrm{x}, \mathrm{x}^{2}, \ldots, \ldots, x^{N}\right.}_{\Omega(x)}] \underbrace{\left[\begin{array}{ccccc}
0 & 1 & 0 & \cdots & 0 \\
0 & 0 & 2 & \cdots & 0 \\
\vdots & \vdots & \vdots & \ddots & \vdots \\
0 & 0 & 0 & \cdots & N \\
0 & 0 & 0 & \cdots & 0
\end{array}\right]}_{M}
$$

and the following formula holds as

$\Omega^{(\mathrm{k})}(\mathrm{x})=\Omega(\mathrm{x}) \mathrm{M}^{\mathrm{k}}, \quad \mathrm{k}=1,2$

where $\Omega^{(\mathrm{i})}(\mathrm{x})$ is denoting the it's derivative of $\Omega(\mathrm{x})$, we have

$u_{N}^{(\mathrm{k})}=\Omega(x) M^{k} D^{t} c, \quad k=1,2$

\section{Application of the Proposed Method}

First, we need to treat the nonlinear term in eqn. (1) by expanding it using Taylor series expansion in the form

$$
e^{ \pm u(x)} \approx 1 \pm u(x)+\frac{u^{2}(x)}{2 !} \pm \frac{u^{3}(x)}{3 !}+\frac{u^{4}(x)}{4 !} \pm \ldots
$$

By substituting the expanded term from eqn. (10) into eqn. (1), the equation becomes

$$
\mathrm{u}^{\prime \prime}(x)+\lambda\left[1 \pm u(x)+\frac{u^{2}(x)}{2 !} \pm \frac{u^{3}(x)}{3 !}+\frac{u^{4}(x)}{4 !} \pm \ldots\right]=0
$$

Second, we will use the shifted chebychev defined on the interval $[0,1]$ in the form

$x_{k}=\frac{1}{2}\left[1-\cos \left(\frac{k \pi}{N}\right)\right], k=0,1, \ldots \ldots, N$ 
After substituting those collocation points into eqn. (11), we reach the following system

$$
\mathrm{u}^{\prime \prime}(x)+\lambda\left[1 \pm u(x)+\frac{u^{2}(x)}{2 !} \pm \frac{u^{3}(x)}{3 !}+\frac{u^{4}(x)}{4 !} \pm \ldots\right]=0
$$

from eqn. (12), we need to approximate the term $\mathrm{u}^{\mathrm{v}}\left(\mathrm{x}_{\mathrm{k}}\right), \mathrm{k}=0,1,2,3 ;:$ : : . We will need the following theorem.

\section{Theorem}

The approximation of the function $\mathrm{u}^{\mathrm{v}}\left(\mathrm{x}_{\mathrm{k}}\right), \mathrm{k}=0,1, \ldots, \mathrm{N}$ can be represented according to the following relation

$$
\begin{aligned}
& \left(\begin{array}{c}
u^{v}\left(x_{0}\right) \\
u^{v}\left(x_{1}\right) \\
\vdots \\
u^{v}\left(x_{N}\right)
\end{array}\right)=\left(\begin{array}{lllll}
u\left(x_{0}\right) & 0 & 0 & \cdots & 0 \\
0 & u\left(x_{1}\right) & 0 & \ldots & 0 \\
0 & 0 & u\left(x_{2}\right) & 0 & 0 \\
\vdots & \vdots & \cdots & \ddots & \vdots \\
0 & 0 & \ldots & 0 & u\left(x_{N}\right)
\end{array}\right)^{v-1}\left(\begin{array}{c}
u\left(x_{0}\right) \\
u\left(x_{1}\right) \\
\vdots \\
u\left(x_{N}\right)
\end{array}\right) \\
& \quad=(\tilde{U})^{v-1} U \\
& \quad=(\tilde{B} \tilde{C})^{v-1}(B C)
\end{aligned}
$$

Where

$$
\begin{gathered}
\tilde{B}=\left(\begin{array}{lllll}
B\left(x_{0}\right) & 0 & 0 & \cdots & 0 \\
0 & B\left(x_{1}\right) & 0 & \cdots & 0 \\
\vdots & \vdots & \cdots & \ddots & \vdots \\
0 & 0 & \cdots & 0 & B\left(x_{N}\right)
\end{array}\right), \tilde{C}=\left(\begin{array}{lllll}
c & 0 & 0 & \cdots & 0 \\
0 & c & 0 & \cdots & 0 \\
0 & 0 & c & 0 & 0 \\
\vdots & \vdots & \cdots & \ddots & \vdots \\
0 & 0 & \cdots & 0 & c
\end{array}\right), \\
B=\left(\begin{array}{llllll}
B_{0}\left(x_{0}\right) & B_{1}\left(x_{0}\right) & B_{2}\left(x_{0}\right) & \cdots & B_{N}\left(x_{0}\right) \\
B_{0}\left(x_{1}\right) & B_{1}\left(x_{1}\right) & B_{2}\left(x_{1}\right) & \cdots & B_{N}\left(x_{1}\right) \\
B_{0}\left(x_{2}\right) & B_{1}\left(x_{2}\right) & B_{2}\left(x_{2}\right) & \cdots & B_{N}\left(x_{2}\right) \\
\vdots & \vdots & \vdots & \ddots & \vdots & \\
B_{0}\left(x_{N}\right) & B_{1}\left(x_{N}\right) & B_{2}\left(x_{N}\right) & \cdots & B_{N}\left(x_{N}\right)
\end{array}\right)
\end{gathered}
$$

By substituting the above theorem into eqn. (12), we reach the following theorem.

\section{Theorem}

If the assumed approximate solution of the problem eqn. (12) is eqn. (8), then the discrete Bernoulli system is

$$
u^{\prime \prime}\left(x_{k}\right)+\lambda\left[u\left(x_{k}\right)+\frac{u^{v}\left(x_{k}\right)}{n !}\right]=f\left(x_{k}\right), 0 \leq k \leq N, n, v=2,3,4 \ldots .
$$

Proof: If we replace each term of (12) with its corresponding approximation given

by eqns.(2), (9) and (13) and substituting $\mathrm{x}=\mathrm{x}_{\mathrm{k}}$ collocation points.

The matrix form for this system is

$\Theta c=F$

Where

$$
\begin{aligned}
& \Theta=\mathrm{BM}^{2}+\lambda\left[\mathbf{B}+(\tilde{\mathbf{B}} \tilde{\mathbf{C}})^{v-1} \mathbf{B}\right], \\
& \text { And } \\
& F=\left(\begin{array}{c}
-\lambda \\
-\lambda \\
\vdots \\
-\lambda
\end{array}\right), \quad \lambda=\left(\begin{array}{ccccc}
\lambda & 0 & 0 & \cdots & 0 \\
0 & \lambda & 0 & \cdots & 0 \\
\vdots & \vdots & \cdots & \ddots & \vdots \\
0 & 0 & \cdots & 0 & \lambda
\end{array}\right) .
\end{aligned}
$$

The matrix form of the boundary conditions represented in eqn. (1) will be in the form

$$
\begin{aligned}
& \mathrm{B}(0)=\left[\mathrm{B}_{0}(0), \mathrm{B}_{1}(0), \mathrm{B}_{2}(0), \ldots, \mathrm{B}_{\mathrm{N}}(0)\right]=0 \\
& \mathrm{~B}(1)=\left[\mathrm{B}_{0}(1), \mathrm{B}_{1}(1), \mathrm{B}_{2}(1), \ldots, \mathrm{B}_{\mathrm{N}}(1)\right]=0
\end{aligned}
$$

By replacing two rows of the augmented matrix $[\Theta: \mathbf{F}]$ with the boundary conditions defined from eqn. (16), we have

$$
\tilde{\Theta}_{c}=\tilde{\mathbf{F}}
$$

Now we have a nonlinear system of $\mathrm{N}+1$ equation in $\mathrm{N}+1$ unknown coefficient $\mathrm{c}$. We can obtain these coefficients by solving the above nonlinear system using the following algorithm.

\section{Algorithm}

1. Input (integer) $\mathrm{N}$.

Input (double) tol.

Input (array) $\mathrm{c}_{\text {old }}=\mathrm{c}_{0}$, (initial approximation, $\mathrm{c}_{0}$ with $\mathrm{N}+1$ dimension, are chosen so that the boundary conditions are satis ed).

2. $\tilde{\Theta}=\left(c_{\text {old }}\right): c_{\text {new }}=\tilde{\mathbf{F}}$ is a linear algebraic equation system which is solved and $c_{\text {new }}$ is found.

Go to (2).

2.1 If $\left|\mathrm{C}_{\text {old }}-\mathrm{C}_{\text {new }}\right|<$ tol then $\mathrm{c}_{\text {new }}=c$, break (the program is finished).

2.2 Else then $\mathrm{c}_{\text {old }} \leftarrow \mathrm{c}_{\text {new }}$.

3. Go to (2).

\section{Numerical Examples}

To illustrate the ability, reliability and the performance of the proposed method for Bratu's problem, some examples are provided. The results reveal that the method is very effective and simple. All computations were carried out using Matlab 2014a on a personal computer. The absolute error can be calculated according to the following

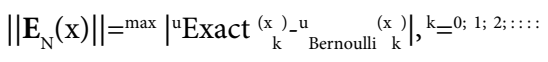

\section{Example 1}

First, we consider the initial value problem in the form $[31,9,25,21,15,46]$

$$
u^{\prime \prime}(x) "-2 e^{u(x)}=0 ; \quad x \in(0,1)
$$

subject to the initial conditions

$$
u^{\prime}(0)=u(0)=0
$$

which has the exact solution given by

$\mathrm{u}(\mathrm{x})=-2 \ln [\cos (\mathrm{x})$.

Table 1 exhibits the maximum absolute error at different values of $\mathrm{N}$ along with the elapsed CPU time in seconds. Also, in Table 2 a comparison between the reported results in $[31,9,25,21,15,46]$ along with our method at $\mathrm{N}=18$. This table indicates that our method provide better results than the other methods. Figure 2 demonstrates the Bernoulli approximate solution versus the exact solution for $\mathrm{x} 2[0 ; 1]$.

\section{Example 2}

Next, we apply our method for the solution of the special form of Bratu equation [4-12,17,25,28,30,33-34,46] 


$$
u^{\prime \prime}(x)+\lambda e^{u(x)}=0, x \in(0,1)
$$

subject to the boundary conditions

$\mathrm{u}(0)=\mathrm{u}(1)=0$.

with the exact solution

\begin{tabular}{|c|c|c|}
\hline $\mathbf{N}$ & $\| \mathrm{E}_{\mathbf{N}} \mathbf{( x )} \boldsymbol{C P U}$ time $\left.\mathbf{( s e c}\right)$ \\
\hline 4 & $1.39189 \mathrm{E}-02$ & 1.264 \\
\hline 6 & $8.70130 \mathrm{E}-04$ & 1.329 \\
\hline 8 & $5.39038 \mathrm{E}-05$ & 1.670 \\
\hline 10 & $3.33058 \mathrm{E}-06$ & 2.310 \\
\hline 12 & $2.05470 \mathrm{E}-07$ & 2.868 \\
\hline 14 & $1.26651 \mathrm{E}-08$ & 3.674 \\
\hline 16 & $7.80110 \mathrm{E}-10$ & 4.469 \\
\hline 18 & $4.80861 \mathrm{E}-11$ & 11.98 \\
\hline
\end{tabular}

Table 1: Maximum absolute error and CPU time for Example 4.1.

\begin{tabular}{|c|c|}
\hline Presented method, N=18 & $4.809 \mathrm{E}-11$ \\
\hline Optimal spline method [9] & $3.450 \mathrm{E}-06$ \\
\hline Restarted Adomian decomposition [15] & $5.745 \mathrm{E}-04$ \\
\hline Optimal perturbation iteration [21] & $4.230 \mathrm{E}-04$ \\
\hline Chebychev wavelet method[25] & $1.528 \mathrm{E}-05$ \\
\hline ASM method [31] & $6.220 \mathrm{E}-07$ \\
\hline Taylor wavelet [46] & $7.801 \mathrm{E}-08$ \\
\hline
\end{tabular}

Table 2: Comparison of maximum absolute error for Example 1.

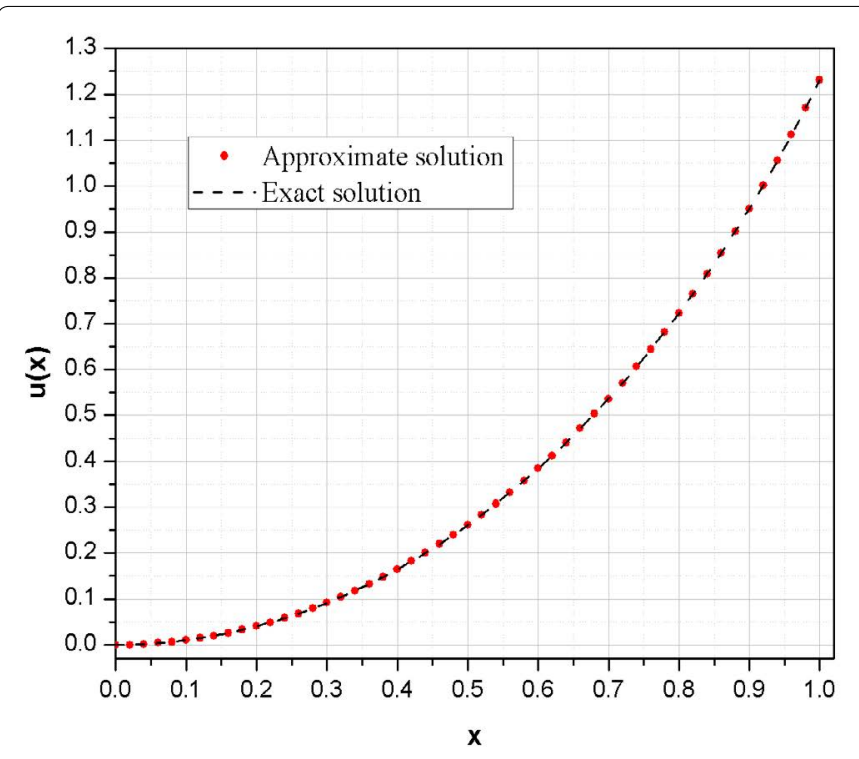

Figure 2: Bernoulli solution and exact solution for example 1.

$$
\mathrm{u}(x)=-2 \operatorname{In}\left[\frac{-\cosh \left(\left(x-\frac{1}{2}\right) \frac{\theta}{2}\right)}{\cosh \left(\frac{\theta}{4}\right)}\right]
$$

The form of the above equation is very familiar and has a tremendous work for solving it as mentioned in the literature. We applied our method with various (Figure 2) values for $=0: 1 ; 0: 5 ; 1$; 2; 3 and 3:51. The computed maximum absolute errors at different values of $\mathrm{N}$ and are tabulated in Table 3 . A comparison with the other methods reported in the literature are presented in Table 4 shows that our method is computationally effective even for $=3: 51$ which is near the critical value. The graph of the approximate solutions for different values of has been plotted in Figure 3 .

\section{Example 3}

Now, we turn our attention to the BVP of Bratu's equation in the form $[21,31]$

$$
u^{\prime \prime}(" x)+\pi^{2} e^{-u(x)}=0, \quad x \in(0,1)
$$

subject to the boundary conditions

$\mathrm{u}(0)=\mathrm{u}(1)=0$.

This equation is a standard Bratu equation for which $\lambda=\pi^{2}>\lambda$ which has two possible solutions in the form $\mathrm{u}(\mathrm{x})=\ln (1 \pm \sin (\mathrm{x}))$. This solution with the negative sign blows up at $\mathrm{x}=0: 5$ so we will use the solution of positive sign which is convergent and bounded in the form

$$
\mathrm{u}(\mathrm{x})=\ln [1+\sin (\mathrm{x})]
$$

Maximum absolute error is tabulated in Table 5 along with the CPU time and a comparison is made in Table 6 between our method along with the other methods in [21,31]. From Table 6, we noticed that our method is more accurate than the other existing methods. Figure 4 demonstrates the Bernoulli approximate solution and the exact which appears to be in good agreement with each other.

\section{Example 4}

Finally, consider another form of Bratu's equation

$u^{\prime \prime}(" x)+\pi^{2} e^{-u(x)}=0, \quad x \in(0,1)$

subject to the boundary conditions

$\mathrm{u}(0)=\mathrm{u}(1)=0$.

with the exact solution

$\mathrm{u}(\mathrm{x})=-\log [1-\cos ((0: 5+\mathrm{x}) \pi)]$.

The maximum absolute error for this problem is tabulated in Table 7

\begin{tabular}{|c|c|c|c|c|c|c|}
\hline $\mathbf{N}$ & $\lambda=\mathbf{0 : 1}$ & $\lambda=\mathbf{0 : 5}$ & $\lambda=\mathbf{1}: \mathbf{0}$ & $\lambda=\mathbf{2 : 0}$ & $\lambda=\mathbf{0}: \mathbf{0}$ & $\lambda=\mathbf{3}: \mathbf{5 1}$ \\
\hline 4 & $2.2697 \mathrm{E}-08$ & $3.4346 \mathrm{E}-06$ & $3.60159 \mathrm{E}-05$ & $5.8666 \mathrm{E}-04$ & $7.4020 \mathrm{E}-03$ & $2.8391 \mathrm{E}-02$ \\
\hline 6 & $7.2250 \mathrm{E}-12$ & $5.3149 \mathrm{E}-09$ & $1.06201 \mathrm{E}-07$ & $2.8664 \mathrm{E}-06$ & $5.3078 \mathrm{E}-05$ & $7.7256 \mathrm{E}-03$ \\
\hline 8 & $3.9100 \mathrm{E}-15$ & $2.4657 \mathrm{E}-11$ & $1.12485 \mathrm{E}-09$ & $8.6920 \mathrm{E}-08$ & $3.1672 \mathrm{E}-06$ & $4.1393 \mathrm{E}-04$ \\
\hline 10 & $2.3922 \mathrm{E}-15$ & $4.7454 \mathrm{E}-13$ & $1.15237 \mathrm{E}-11$ & $1.5694 \mathrm{E}-09$ & $8.8354 \mathrm{E}-08$ & $9.0424 \mathrm{E}-06$ \\
\hline 12 & $2.3939 \mathrm{E}-15$ & $4.4039 \mathrm{E}-13$ & $3.3323 \mathrm{E}-12$ & $1.2423 \mathrm{E}-10$ & $4.4392 \mathrm{E}-09$ & $1.1319 \mathrm{E}-06$ \\
\hline 14 & - & - & $3.4237 \mathrm{E}-12$ & $6.4105 \mathrm{E}-12$ & $3.1209 \mathrm{E}-10$ & $7.8326 \mathrm{E}-08$ \\
\hline 16 & - & - & - & $5.9817 \mathrm{E}-12$ & $1.2622 \mathrm{E}-10$ & $7.0247 \mathrm{E}-09$ \\
\hline 18 & - & - & - & - & - & $5.5903 \mathrm{E}-10$ \\
\hline
\end{tabular}

Table 3: Maximum absolute error at different $\lambda$ Example 2. 
Citation: EL-Gamel M, Adel W, EL-Azab MS (2018) Collocation Method Based on Bernoulli Polynomial and Shifted Chebychev for Solving the Bratu Equation. J Appl Computat Math 7: 407. doi: 10.4172/2168-9679.1000407

Page 5 of 7

\begin{tabular}{|c|c|c|c|}
\hline Method & $\lambda=1: 0$ & $\lambda=2: 0$ & $\lambda=3: 51$ \\
\hline Presented method, $\mathrm{N}=14$ & 3.4237E-12 & $6.4105 \mathrm{E}-12$ & 5.5903E-10 \\
\hline Sinc galerkin [10] & $2.010 \mathrm{E}-10$ & $1.801 \mathrm{E}-11$ & $1.4528 \mathrm{E}-07$ \\
\hline Optimal spline [9] & $1.810 \mathrm{E}-07$ & $3.940 \mathrm{E}-11$ & $x$ \\
\hline Chebychev wavelet [25] & $x$ & 5.487E-06 & $x$ \\
\hline Spline method [8] & 8.773E-05 & 8.971E-04 & $6.890 \mathrm{E}-06$ \\
\hline Lie group shooting [12] & $1.018 \mathrm{E}-06$ & $5.220 \mathrm{E}-06$ & 7.305E-05 \\
\hline B-spline method [4] & 8.892E-06 & $5.561 \mathrm{E}-05$ & $1.350 \mathrm{E}-01$ \\
\hline Restarted Adomian [17] & $9.410 \mathrm{E}-07$ & $2.300 \mathrm{E}-04$ & $x$ \\
\hline Adomian with Taylor [17] & 4.900E-06 & $6.800 \mathrm{E}-04$ & $x$ \\
\hline Spline method [6] & $2.178 \mathrm{E}-06$ & 7.264E-07 & $x$ \\
\hline Variational iteration [28] & $4.210 \mathrm{E}-05$ & 1.416E-03 & $x$ \\
\hline Parametric spline [5] & $5.870 \mathrm{E}-10$ & 3.530E-08 & $x$ \\
\hline Finite di erence [30] & $5.703 \mathrm{E}-10$ & 2.096E-09 & $6.21 \mathrm{E}-07$ \\
\hline Neural network [34] & $3.20 \mathrm{E}-03$ & 4.95E-03 & 1.76E-02 \\
\hline Particle swarm shooting [35] & $1.150 \mathrm{E}-08$ & 6.71E-09 & $3.58 \mathrm{E}-06$ \\
\hline Mexican Hat wavelet [33] & 1.90E-08 & 3.75E-08 & $1.72 \mathrm{E}-05$ \\
\hline Taylor wavelet [46] & $7.760 \mathrm{E}-12$ & 1.190E-09 & $1.31 \mathrm{E}-06$ \\
\hline Matlab routine bvp4c [47] & 2.47E-07 & $1.33 \mathrm{E}-06$ & 1.43E-02 \\
\hline Mathematica routine NDsolve & 5.71E-09 & $5.88 \mathrm{E}-09$ & 3.01E-07 \\
\hline
\end{tabular}

Table 4: Comparison of maximum absolute error at different $\lambda$ for Example 2.

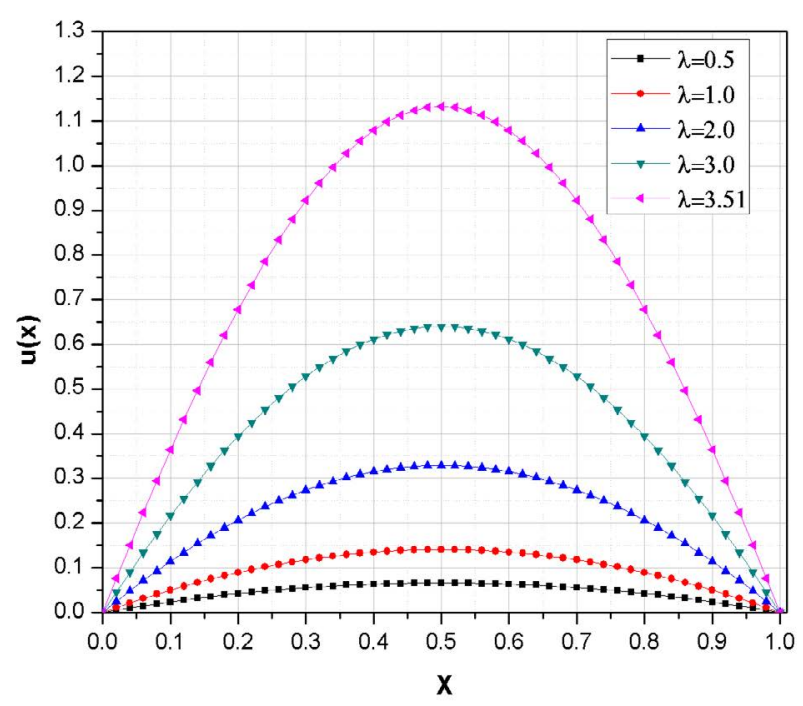

Figure 3: For $\lambda=0.5,1.0,2.0,3.0$ and $\lambda=3.51$, the approximate solution of the purposed method for $\mathrm{N}=14$.

\begin{tabular}{|c|c|c|}
\hline $\mathbf{N}$ & $\mathbf{k E}_{\mathbf{N}}(\mathbf{x}) \mathbf{k}$ & $\mathbf{C P U}$ time $\mathbf{( s e c})$ \\
\hline 4 & $2.20480 \mathrm{E}-03$ & 1.264 \\
\hline 6 & $6.78106 \mathrm{E}-05$ & 1.329 \\
\hline 8 & $2.64416 \mathrm{E}-06$ & 1.670 \\
\hline 10 & $1.13839 \mathrm{E}-07$ & 2.310 \\
\hline 12 & $5.62457 \mathrm{E}-09$ & 2.868 \\
\hline 14 & $2.64951 \mathrm{E}-10$ & 3.674 \\
\hline 16 & $4.76705 \mathrm{E}-11$ & 4.469 \\
\hline 18 & $9.04055 \mathrm{E}-13$ & 11.98 \\
\hline
\end{tabular}

Table 5: Maximum absolute error and CPU time for Example 3.

\begin{tabular}{|c|c|}
\hline Presented method, $\mathrm{N}=18$ & $9.04055 \mathrm{E}-13$ \\
\hline Optimal perturbation iteration [21] & $8.886 \mathrm{E}-07$ \\
\hline ASM method [31] & $8.034 \mathrm{E}-06$ \\
\hline GA-ASM method [31] & $3.449 \mathrm{E}-05$ \\
\hline GA method [31] & $2.088 \mathrm{E}-02$ \\
\hline
\end{tabular}

Table 6: Comparison of maximum absolute error for Example 3.

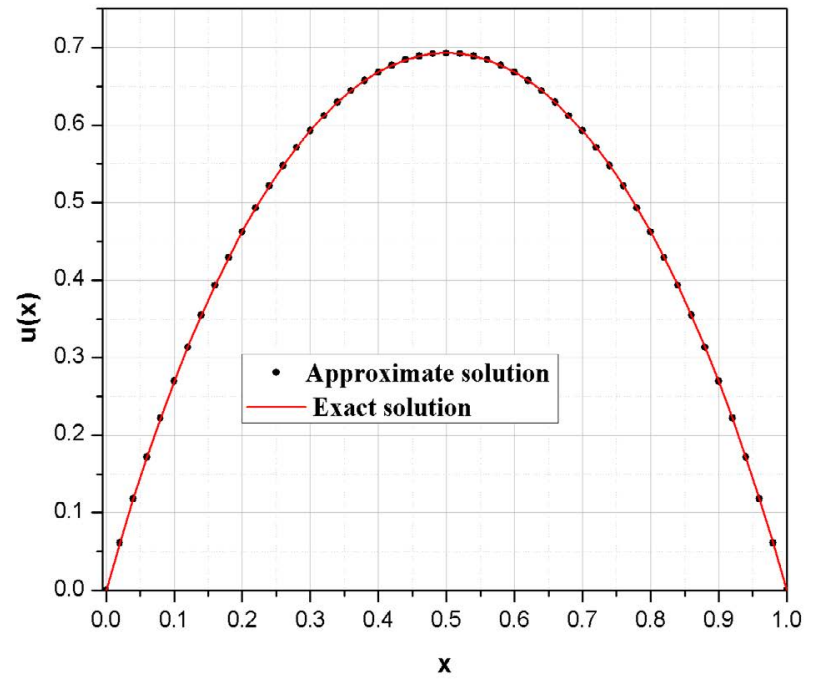

Figure 4: Bernoulli solution and exact solution for example 3.

\begin{tabular}{|c|c|c|}
\hline $\mathbf{N}$ & $\left\|\mathrm{E}_{\mathbf{N}}(\mathbf{x})\right\|$ & $\mathbf{C P U}$ time $(\mathbf{s e c})$ \\
\hline 4 & $2.20480 \mathrm{E}-03$ & 1.065 \\
\hline 6 & $6.78106 \mathrm{E}-05$ & 1.269 \\
\hline 8 & $2.64416 \mathrm{E}-06$ & 1.696 \\
\hline 10 & $1.13839 \mathrm{E}-07$ & 2.266 \\
\hline 12 & $5.62457 \mathrm{E}-09$ & 2.859 \\
\hline 14 & $2.64951 \mathrm{E}-10$ & 3.624 \\
\hline 16 & $4.76705 \mathrm{E}-11$ & 4.794 \\
\hline 18 & $7.46625 \mathrm{E}-13$ & 5.573 \\
\hline
\end{tabular}

Table 7: Maximum absolute error and CPU time for Example 4.

at different values of $\mathrm{N}$ along with the $\mathrm{CPU}$ time. A comparison is made along with other methods which is given in the literature in Table 8 which proves the applicability of the purposed algorithm of providing good results. Figure 5 demonstrates the Bernoulli approximate solution and the exact which appears to be in good agreement with each other. 
Citation: EL-Gamel M, Adel W, EL-Azab MS (2018) Collocation Method Based on Bernoulli Polynomial and Shifted Chebychev for Solving the Bratu Equation. J Appl Computat Math 7: 407. doi: 10.4172/2168-9679.1000407

Page 6 of 7

\begin{tabular}{|c|c|}
\hline Presented method, $\mathrm{N}=18$ & $7.46625 \mathrm{E}-13$ \\
\hline Sinc-Galerkin [10] & $8390 \mathrm{E}-12$ \\
\hline Optimal Spline method [9] & $4.341 \mathrm{E}-10$ \\
\hline GA method [31] & $1.293 \mathrm{E}-06$ \\
\hline Taylor Wavelet [46] & $1.434 \mathrm{E}-07$ \\
\hline
\end{tabular}

Table 8: Comparison of maximum absolute error for Example 4.

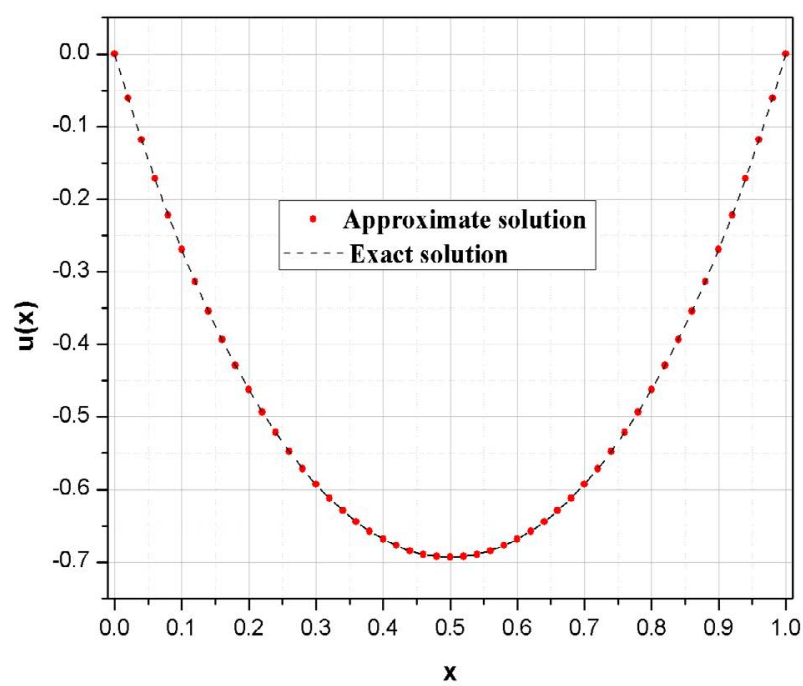

Figure 5: Approximate solution versus exact solution for example 4.

\section{Conclusion}

In this paper, we showed that Bernoulli-collocation method can be utilized to and an approximate solution of the nonlinear Bratu's type equations. The method reduces the problem into a system of nonlinear algebraic equations and this system is solved using a novel technique. Also, the efficiency of the method with respect to the other method was shown. In comparison to other methods, we illustrated that Bernoullicollocation method has very high accuracy.

\section{References}

1. Bratu G (1914) Sur les équations intégrales non linéaires. Bull Soc Math France 42: 191.

2. Jacobsen J, Shmitt K (2002) The Liouville-Bratu-Gelfand problem for radial operators. J Differential Equations 184: 283-298.

3. Buckmire R (2004) Applications of Mickens finite difference to several related boundary value problems. Advances in the Applications of Nonstandard Finite Difference Schemes 147: 47-87.

4. Caglar H, Caglar N, Ozer M, Valarstos A, Anagnostopoulos A (2010) B-spline method for solving Bratu's problem. Int J Compu Math 87: 1885-1891.

5. Zarebnia M, Sarvari Z (2012) Parametric spline method for solving Bratu's problem. Int J Non-linear Sci 14: 3-10.

6. Zarebnia M, Hoshyar M (2014) Solution of Bratu-type equation via spline method. Act Univ Apul 37: 61-72.

7. Alayed O, Yuan T, Saaban A (2016) Quintic spline method for solving linear and nonlinear boundary value problems. Sains Maly 45: 1007-1012.

8. Al-Towaiq M, Alayed O (2014) An e cient algorithm based on the cubic spline for the solution of Bratu-type equation. J Interdiscip Math 17: 471-484.

9. Abukhaled M, Khuri S, Sayfy A (2012) Spline-based numerical treatments of Bratu-type equations. Pales J Math 1: 63-70.

10. Rashidinia J, Maleknejad K, Taheri N (2013) Sinc-Galerkin method for numerical solution of the Bratus problems. Numer Algor 62: 1-11.
11. Zarebnia M, Sajiadian M (2014) Convergence of the Sinc-Galerkin method for the Bratu equation. Chiang Mai J Sci 41: 714-723.

12. Abbasbandy S, Hashemi M, Liu C (2011) The lie-group shooting method for solving the Bratu equation, Commun. Nonlinear Sci Numer Simul 16: 4238 4249 .

13. Wazwaz A (2005) Decomposition method for a reliable treatment of the Bratutype equations. Appl Math Compu 166: 652-663.

14. Adesanya S, Babadipe E, Arekete S (2013) A new result on Adomian decomposition method for solving Bratus problem. Math Meth Model 3: 116-120.

15. Vahidi, Hasanzade M (2012) Restarted Adomians decomposition method for the Bratu-type problem. Appl Math Sci 6: 479-486.

16. Deeba E, Khuri S, Xie S (2000) An algorithm for solving boundary value problems. J. Comput Phys 159 125-138.

17. Al-Mazmumy M, Al-Mutairi A, Al-Zahrani K (2017) Ancient decomposition method for solving Bratus boundary value problem. Amer J Compu Math 7 : 84-93

18. Kashkari B, Abbas S (2017) Solution of initial value problem of Bratus type equation using modifications of Homotopy Perturbation method. Int J Comp Appl 162: 44-49.

19. Abolarin O (2013) New improved variational Homotopy Perturbation method for Bratu-type problems. Amer J Compu Math 3: 110-113

20. Feng X, He Y, Meng J (2008) Applications of Homotopy Perturbation method to the Bratu-type equations, Topol Methods Nonlinear Anal 31: 243-252.

21. Deniz S, Bildik N (2018) Optimal perturbation iteration method for Bratu-type problems. J King Saud University. Science 30: 91-99.

22. Syam, Hamdan A (2006) Ancient method for solving Bratu's equation. App Math Compu 176: 704-713.

23. Wazwaz (2016) The successive differentiation method for solving Bratu's equation and Bratu type equations. Romanian J Phys 61: 774-783.

24. Hariharan G (2013) Ancient Wavelet method for initial value problems of Bratutype arising in engineering. Appl Math Sci 7: 2121-2130.

25. Yang, Hou J (2013) Chebyshev wavelets method for solving Bratus problem Bound Value Probl p: 142.

26. Venkatesh S, Ayyaswamy S, Balachandar S (2012) The Legendre wavelet method for solving initial value problems of Bratu-type. Compu Math Appl 63: 1287-1295.

27. Olayiwola M, Akinpelu F, Gbolagade A (2012) Modified variational iteration method for the solution of a class of differential equations. Amer J Compu App Math 2: 228-231.

28. Das N, Singh R, Wazwaz A, Kumar J (2016) An algorithm based on the variational iteration technique for the Bratu-type and the Lane-Emden problems. J Math Chem 54: 527-551.

29. Batiha (2010) Numerical solution of Bratu-type equations by the variational itreation method. Hacet J Math Stat 39: 23-29.

30. Temimi H, Ben-Romdhane M (2016) An iterative finite difference method for solving Bratus problem. J Compu Appl Math 292: 76-82.

31. Raja M, Samar R, Alaidarous E, Shivanian E (2016) Bio-inspired computing platform for reliable solution of Bratu-type equations arising in the modelling of electrically conducting solids. Appl Math Model 40: 5964-5977.

32. Ullah M, Serra-Capizzano S, Ahmed F (2015) An ancient multi-step iterative method for computing the numerical solution of systems of nonlinear equations associated with odes. Appl Math Comput 250: 249-259.

33. Masood Z, Majeed K, Samar R, Raja M (2017) Design of Mexican Hat wavelet neural networks for solving Bratu type nonlinear systems. Neurocomputing 221: 1-14.

34. Kumar M, Yadav N (2015) Numerical solution of Bratu's problem using multilayer perceptron Neural Network method. Natl Sci Lett 38: 425-428.

35. Xu Y, Li X, Zhang L (2014) The particle swarm shooting method for solving the Bratus problem. J Algorithms Comput Technol 9: 291-302.

36. Boyd J (2003) Chebychev polynomial expansions for simultaneous approximation of two branches of a function with application of the onedimensional Bratu equation. Appl Math Comput 142: 189-200. 
Citation: EL-Gamel M, Adel W, EL-Azab MS (2018) Collocation Method Based on Bernoulli Polynomial and Shifted Chebychev for Solving the Bratu Equation. J Appl Computat Math 7: 407. doi: 10.4172/2168-9679.1000407

Page 7 of 7

37. Boyd JP (1986) An analytical and numerical study of the two-dimensional Bratu's equation. J Sci Comput 1: 183-206

38. Erdem K, Yalcinbas S, Sezer M (2013) A Bernoulli polynomial approach with residual correction for solving mixed linear Fredholm integro-differentialdifference equations. Int J Difference.

39. Tohidi, Bhrawy A, Erfani K (2013) A collocation method based on Bernoulli operational matrix for numerical solution of generalized pantograph equation. Appl Math Model 37: 4283-4294.

40. Tohidi, Kiliman A (2013) A Collocation method based on the Bernoull operational matrix for solving nonlinear BVP's which arise from the problems in calculus of variation. Math Problems Eng.

41. Bhrawy, Tohidi E, Soleymani F (2012) A new Bernoulli matrix method for solving high-order linear and nonlinear Fredholm integro-differential-difference equations with piecewise intervals. Appl Math Comput 219: 482-497.

42. Toutounian, Tohidi E (2013) A new Bernoulli matrix method for solving second order linear partial differential equations with the convergence analysis. Appl Math Comput 223: 298-310.

43. Mirzaee, S Bimesl (2014) An ancient numerical approach for solving systems of high-order linear Volterra integral equations. Scientia Iranica 21: 2250-2263.

44. Golbabai, Panjeh S (2015) An ancient method based on operational matrices of Bernoulli polynomials for solving matrix differential equations. Comp Appl Math 34: 159-175.

45. Napoli (2016) Solutions of linear second order initial value problems by using Bernoulli polynomials. Appl Numer Math 99: 109-120.

46. Keshavarz E, Ordokhani $Y$, Razzaghi M (2018) The Taylor wavelets method for solving the initial and boundary value problems of Bratu-type equations. Appl Numer Math 128: 205-216.

47. Shampine L, Reichelt M, Kierzenka J (2000) Solving boundary value problems for ordinary differential equations in MATLAB with bvp4c. 